\title{
Existence of a Critical Carbon Number in the Aging of a Wax-Oil Gel
}

\author{
Probjot Singh, Arm Youyen, and H. Scott Fogler \\ Dept. of Chemical Engineering, University of Michigan, Ann Arbor, MI 48109
}

\begin{abstract}
A fundamental study was carried out to understand the aging (or hardening) of the wax-oil gels formed in the subsea pipelines during the flow of crude oil from offshore wells to shore. The aging process is a counterdiffusion phenomenon where there exists a critical carbon number (CCN), and wax molecules with carbon numbers greater than the CCN diffuse into the gel matrices and vice versa. Using a careful analysis of carbon number distributions of gel deposits, collected from a cold finger after various deposition time intervals, the CCN for the wax-oil system was obtained. A mathematical model, based on a modified version of UNIQUAC model, was developed to predict the $C C N$ for wax-oil systems. The size of the interaction units for $n$-alkanes in the solid-phase UNIQUAC model was found to be a strong function of the mean carbon number in the solid phase.
\end{abstract}

\section{Introduction}

Crude oil is a complex mixture of numerous hydrocarbons that are divided into different groups such as paraffins, aromatics, napththenes, resins, and asphaltenes. Among these groups of hydrocarbons, high molecular weight paraffins (waxes) are responsible for various problems that are encountered during transportation and processing of these complex fluids. The high molecular weight paraffins have a low solubility in most aromatic, naphthenic, and other organic solvents at room temperature. At offshore reservoir temperatures $\left(70-150^{\circ} \mathrm{C}\right)$, the solubility of these compounds is sufficiently high to keep these molecules fully dissolved in the mixture and the crude oil behaves as a Newtonian fluid with a low viscosity. Once the crude oil leaves the reservoir and flows through subsea pipelines, its temperature begins to drop due to the cooler environment on the ocean floor. This decrease in temperature causes waxes to deposit on the wall of the pipeline and results in plugging of the pipeline, as shown in Figure 1.

The solubility of high molecular weight paraffins decreases drastically with decreasing temperatures; as a result, these molecules start forming stable crystals at low temperatures. The crystallization of paraffins leads to the formation of gels with a complex morphology (Abdallah et al., 2000). The gela-

Correspondence concerning this article should be addressed to H. S. Fogler. tion is due to the flocculation of orthorhombic wax crystallites that appear in the solution while cooling (Dirand et al., 1998). An observation under a cross-polarized microscope revealed that the crystallites have structures of platelets that overlap and interlock (Holder and Winkler, 1965). Studies on distillate fuels show that as little as $2 \%$ of the precipitated wax is required to form the gel (Holder and Winkler, 1965). The deposition of these gels gradually plugs up the pipeline leaving a small opening for the flow (c.f. Figure 1).

The composition of the gel, as well as the rate of gelation, depends on the conditions at which the gel is deposited. The wax-oil mixture gels with cooling, and the nature of this gel depends strongly on the cooling rate (Singh et al., 1999; Chang et al., 2000). The incipient wax-oil gel deposit contains a significant amount of oil trapped in a 3-D network structure of the wax crystals. Hence, the gel behaves as a porous medium (c.f. Figure 2) in which hydrocarbons having a carbon number greater than the critical carbon number (CCN) continue to diffuse into the deposit and hydrocarbons having a carbon number less than the CCN diffuse out of the deposit.

A mixture of model wax and model oil has been used in a flow loop setup in the laboratory (Singh et al., 2000). The samples of the wax-oil gel deposits collected from the wall of the tubing at various times, were analyzed using high-temperature gas chromatography (HTGC) (Singh et al., 2000). To determine the changes in the carbon number distributions of 


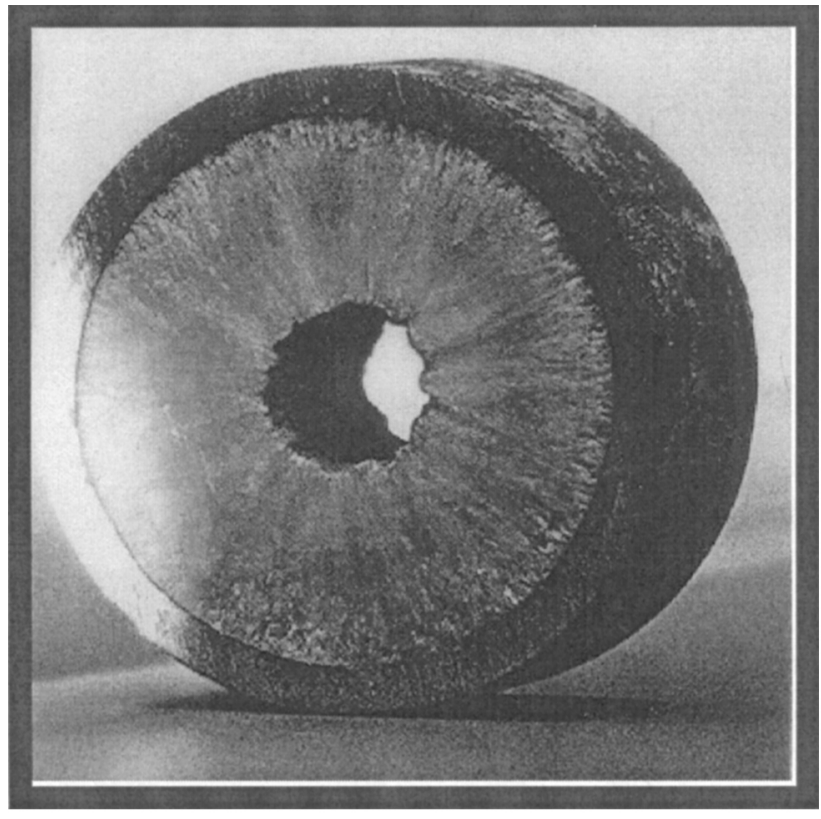

Figure 1. Cross-sectional view of plugged pipelines.

the gel deposits with time, the distribution of the oil sample is subtracted from those of the gel deposits (c.f. Figure 3). It is observed that the mass fractions of hydrocarbons having carbon number greater than 28 increase with time and mass fractions of those having carbon number less than 28 decrease with time. Figure 4 shows that the hydrocarbons having carbon number greater than 28 diffuse into the gel deposit, and those having carbon number less than 28 diffuse out of the gel deposit. Thus, this aging process in the flow loop is a counterdiffusion phenomenon. At the given operating conditions, the critical carbon number is 28 (Singh et al., 2000). The aging of the gel deposit hardens the deposit with time and makes the remediation process more challenging.

The mechanical strength and thermal properties of the deposited gel are important parameters for the selection of the type of techniques to remove the deposit. Mechanical pigs can easily get trapped in the pipeline by hard gel deposits. However, thin deposits of soft gels may easily be removed by pigs. Likewise, thermal removal techniques may be most efficient in the removal of deposits having low melting points and low heats of fusion. One such thermal technique to remove the wax deposits has been described by Singh and Fogler

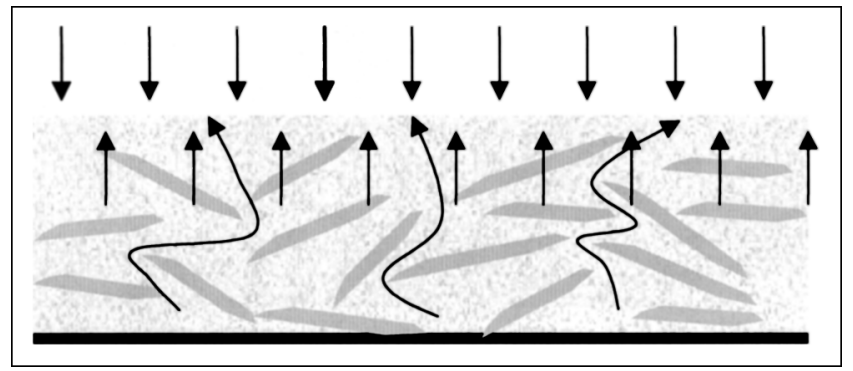

Figure 2. Aging process of wax-oil gel deposit.

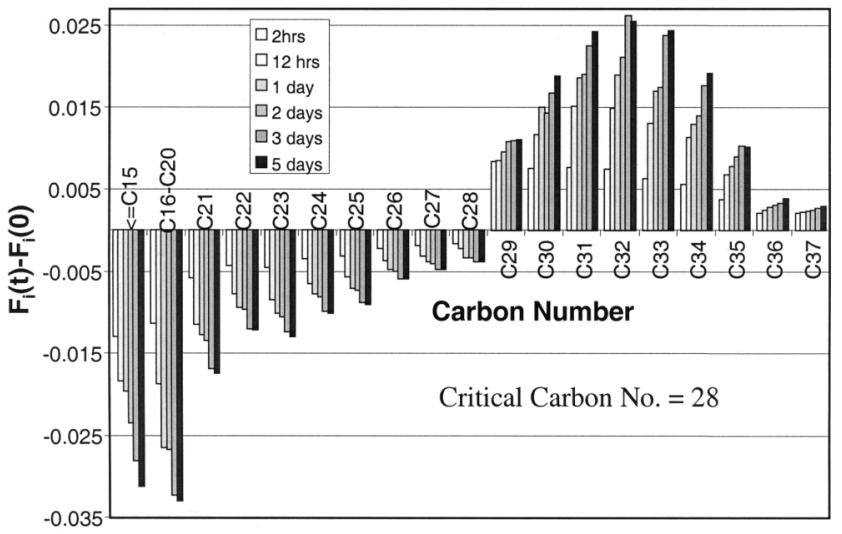

Figure 3. Changes in carbon number distribution of gel deposits collected from the flowloop for various times.

(1998). The critical carbon number $(\mathrm{CCN})$ of the crude oil system dictates the mechanical, as well as thermal, properties of the deposit. A system with a higher value of $\mathrm{CCN}$ results in an aged gel deposit having a higher melting point and a higher mechanical strength. Hence, the prediction of the $\mathrm{CCN}$ of the crude oil system is a very important asset in developing and selecting the appropriate remediation technique.

Several methods have been published concerning the prediction of wax formation in both crude oils and fuels. A large number of these models are, however, just empirical correlations relating wax appearance temperature (that is, cloud point temperature) with fluid properties. During the last few years, a number of thermodynamic models, which predict the wax precipitation from the wax-oil mixtures, have been proposed in the literature. The first model developed by Won (1985) predicts solid-liquid equilibria of hydrocarbons using the ideal solution assumption. In a later article, Won (1986) used a modified regular solution theory for the solid-liquid equilibria, the Soave-Redlich-Kwong (SRK) equation of state (Soave, 1972) for the vapor-liquid equilibria and a modified solubility parameter in order to take the nonideality of solid solutions into account. Hansen (1988) applied a polymer solution theory for the oil (liquid) phase, while the wax (solid) phase was assumed to be an ideal mixture. The measured

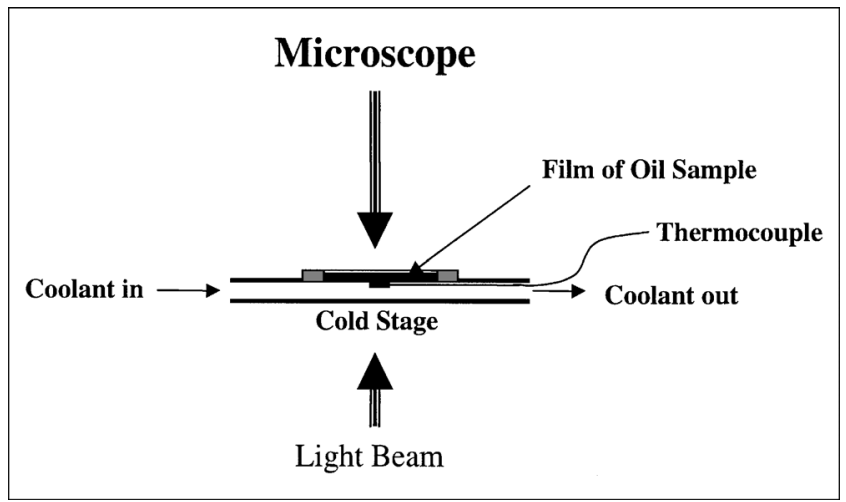

Figure 4. Cross-polarized light microscope apparatus. 
cloud points were used to determine the interaction parameters in their model, and the calculated and measured cloud points were, therefore, found in a reasonably good agreement.

Coutinho et al. (1995) evaluated the activity coefficient models to describe the liquid-phase nonideality for mixtures of alkanes. They concluded that the original Flory-Huggins model, regular solution theory, ideal solution theory, modified UNIFAC, and original Entropic free-volume model are not appropriate for the description of the liquid phase in alkanes systems. The Flory free-volume and a modified version of Entropic free-volume have been found to be the simplest and the most reliable models (Coutinho et al., 1995).

A number of studies (Dorset, 1990; Snyder et al., 1992) showed that when binary normal alkane mixtures are cooled, the precipitate is thermodynamically unstable and segregates into two solid phases, provided that the chain-length difference between the two alkanes exceeds a certain value. Hansen et al. (1991) observed phase transitions of precipitated wax from North Sea crude oils. Based on the above observations, Lira-Galeana et al. (1996) developed a thermodynamic multisolid-wax model. In this model, each solid phase is described as a pure component which does not mix with other solid phases. Dirand et al. (1998) performed the x-ray diffraction analyses for multicomponent paraffin wax and observed the solid-solid transition of orthorhombic crystals. The wax precipitate segregates into two phases provided that the chainlength difference between two alkanes is about three carbon atoms (Coutinho, 1999).

Pauly et al. (1998) stated that a solid solution model in which the solid state is described by the Wilson equation leads to a satisfactory representation of narrow paraffin distribution. However, when the paraffin distribution widens out, the nonideality of solutions increases and the model overestimates the precipitation of the lightest components. To overcome this problem, assuming that the high nonideality between the heaviest and the lightest paraffins leads to the coexistence of several solid solutions, Coutinho (1999) proposed to use the UNIQUAC Model instead of the Wilson equation. $\mathrm{He}$ assumed that the number of $\mathrm{CH}_{2}$ interaction units in a representative interaction unit for $n$-alkanes in the solid phase UNIQUAC model is equal to 10 . However, our research shows that the optimum number of $\mathrm{CH}_{2}$ interaction units in a representative interaction unit for $n$-alkanes in the solidphase UNIQUAC model is a strong function of the mean carbon number in the solid phase.

This study focuses on a physical understanding of the aging process of the gel deposit where these exists a critical carbon number $(\mathrm{CCN})$ indicating the counterdiffusion phenomenon of this process. The model systems of wax and oil were used in a series of laboratory cold finger experiments to verify the physics of the aging process of the gel deposits. A thermodynamic model was developed to predict the cloud point temperature, as well as the CCNs of model oil systems. The theory shows a good agreement with the experimental results.

\section{Critical Carbon Number}

Waxy crude oil is a mixture of hydrocarbons with a broad molecular weight distribution (carbon number distribution). When a hot crude oil, coming out from an oil reservoir at a temperature higher than the cloud point, comes in contact with a cold sub-sea pipe wall, it instantly precipitates and forms a gel layer on the wall. The trapped oil in the incipient gel deposit is connected to the bulk oil through the gel pores that open up at the gel interface. Due to the formation of the solid phase, the trapped oil becomes deleted of certain heavier hydrocarbons as compared to the bulk oil. The minimum carbon number of these heavier hydrocarbons is called CCN. The difference in the concentration of these heavier hydrocarbons leads to a flux of these heavier molecules from the bulk oil to the trapped oil. the formation of the solid phase also makes the trapped oil rich in the hydrocarbons below the CCN. Similarly, the difference in the concentration of these lighter hydrocarbons leads to a flux of the lighter molecules from the trapped oil to the bulk oil. This counterdiffusion process leads to the aging (hardening) of the gel deposit. A mathematical definition of the CCN (Eq. A14) and a concise mathematical analysis is given in Appendix.

\section{Wax Deposition}

Waxy oil is a mixture of hydrocarbons of varying carbon numbers. When this mixture is cooled to a certain temperature, a fraction of hydrocarbons precipitates out as stable crystals to form a gel, with the remaining hydrocarbons trapped in the gel network (Holder and Winkler, 1965). The formation of such gels on a cold surface is the first step of the wax deposition process. The trapped liquid acts as a medium for further diffusion of the heavier molecules into the gel. This diffusion of heavier molecules (having carbon number greater than the $\mathrm{CCN}$ ) is accompanied by the counterdiffusion of the trapped oil (lighter hydrocarbons) out of the deposit. This process leads to an increase in the fraction of molecules with carbon number greater than the $\mathrm{CCN}$ and a decrease in the fraction of molecules with carbon number lower than the $\mathrm{CCN}$, in the gel deposit. Hence, the wax content of the gel deposit increases with time. The wax deposition process can be described by the following steps:

(1) Gelation of the waxy oil (formation of an incipient gel layer) on the cold surface.

(2) Diffusion of waxes towards the gel layer from the bulk.

(3) Internal diffusion of these molecules (hydrocarbons with carbon number greater than the $\mathrm{CCN}$ ) through the trapped oil.

(4) Precipitation of these molecules inside the deposit.

(5) Counterdiffusion of de-waxed oil (hydrocarbons with carbon number lower than the $\mathrm{CCN}$ ) out of the gel layer.

Steps 3 to 5 lead to a gradual increase of the solid fraction of the deposit, which results in the hardening of the deposit. The CCN depends on the composition of the crude oil, as well as the operating conditions, such as wall temperature. As the wall temperature is increased, the solubility of the paraffin molecule also increases resulting in an increase in the $\mathrm{CCN}$. A crude oil system with a higher value of the $\mathrm{CCN}$ results in an aged deposit having a higher value of the average carbon number and, therefore, a higher difficulty in removing the deposit. In order to select the appropriate technique to remove the deposit in the pipeline, the CCN must be evaluated. Thus, prediction of the $\mathrm{CCN}$ of the wax deposits is very essential. 


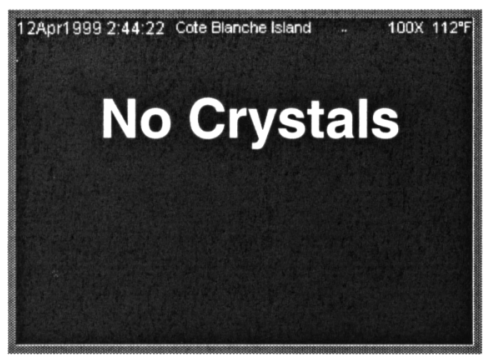

(a)

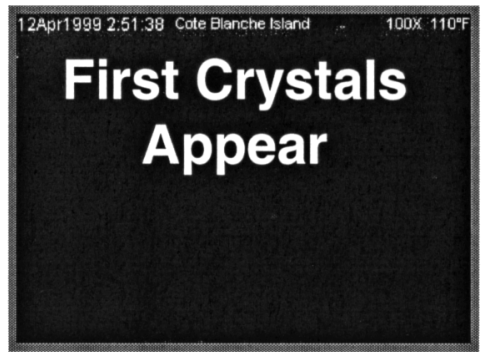

(b)

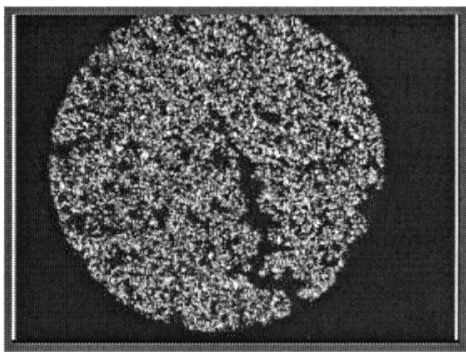

(c)

Figure 5. Images of the wax-oil mixture obtained using the cross-polarized light microscope. (a) $T>T_{\text {cloud }}$; (b) $T \approx$ $T_{\text {cloud }}$; (c) $T<T_{\text {cloud }}$.

\section{Experiment}

\section{Materials}

Oil Solvent. Dodecane with purity of $99+\%$ and specific gravity of 0.875 from Aldrich Chemical Company was used as the model solvent in the cold finger experiments.

Paraffin Waxes. There were two waxes used in this work: Wax No. 1 from Aldrich Chemical Company with a melting point of $55^{\circ} \mathrm{C}$ and Wax No. 2 from Mobil Company with a melting point of $60^{\circ} \mathrm{C}$. The carbon number distributions of these waxes were obtained by a Varian 3800 high-temperature gas chromatograph (HTGC) and are shown in Table 1. High-temperature high-resolution gas chromatography is commonly used to characterize paraffin deposits in petroleum production pipelines (Neto et al., 1994). The carbon number distribution of Wax No. 1 had a range from C21 to C36, while Wax No. 2 had the distribution in a range of C23 to C38. The mean carbon numbers of the two waxes are 26 and 30, respectively.

\section{Cloud Point Measurements Cross-polarized light microscope}

The cross-polarized light microscope (Zeiss PhotoScope 2) coupled with a temperature-control cooling stage (c.f. Figure 4) was used to measure the cloud point of the synthetic wax-oil mixtures by detecting the formation of the first crystal. The temperature at which a wax-oil mixture is a saturated solution is defined as the cloud point temperature. When the temperature of the wax-oil mixture goes below the cloud

Table 1. Carbon Number Distribution (Weight Fraction) of the Wax No. 1 and 2

\begin{tabular}{|c|c|c|c|c|c|}
\hline$n$-Alkanes & Wax No. 1 & Wax No. 2 & $n$-Alkanes & Wax No. 1 & Wax No. 2 \\
\hline$n-\mathrm{C}_{21}$ & 0.008 & 0 & $n-\mathrm{C}_{30}$ & 0.045 & 0.162 \\
\hline$n-\mathrm{C}_{22}^{21}$ & 0.043 & 0 & $n-\mathrm{C}_{31}$ & 0.031 & 0.148 \\
\hline$n-\mathrm{C}_{23}^{22}$ & 0.095 & 0.005 & $n-\mathrm{C}_{32}$ & 0.022 & 0.104 \\
\hline$n-C_{24}$ & 0.149 & 0.014 & $n-\mathrm{C}_{33}$ & 0.013 & 0.069 \\
\hline$n-\mathrm{C}_{25}$ & 0.158 & 0.027 & $n-\mathrm{C}_{34}$ & 0.009 & 0.040 \\
\hline$n-\mathrm{C}_{26}$ & 0.149 & 0.049 & $n-\mathrm{C}_{35}$ & 0.006 & 0.017 \\
\hline$n-\mathrm{C}_{27}$ & 0.116 & 0.084 & $n-\mathrm{C}_{36}$ & 0.005 & 0.006 \\
\hline$n-\mathrm{C}_{28}$ & 0.087 & 0.121 & $n-\mathrm{C}_{37}$ & 0 & 0.003 \\
\hline$n-\mathrm{C}_{29}$ & 0.064 & 0.147 & $n-\mathrm{C}_{38}$ & 0 & 0.001 \\
\hline
\end{tabular}

point, waxes start precipitating out of the solution as wax crystals.

A wax-oil mixture containing a certain weight fraction of wax in dodecane is prepared. Initially, the wax-oil mixture is a clear solution at high temperature (c.f. Figure 5a). Then, the temperature is gradually decreased until the first wax crystal precipitates out, which is observed by the crosspolarized light microscope (c.f. Figure 5b). The temperature at which the first crystal is observed under the microscope is recorded as a cloud point temperature of the particular waxoil mixture.

Wax No. 1 and Wax No. 2 were separately dissolved in dodecane and the solutions of various concentrations were prepared. The cross-polarized light microscope apparatus was used to determine the cloud point temperature of the wax-oil mixtures. Figure 6 shows the cloud point temperatures of Wax No. 1 and Wax No. 2 in dodecane at various concentrations. It can be clearly seen that the solubility of both waxes in dodecane solvent is a strong function of temperature. For the whole range of wax concentration, the mixtures of Wax No. 2 and dodecane have higher cloud point temperatures than those of Wax No. 1 (c.f. Figure 6). This difference is due to

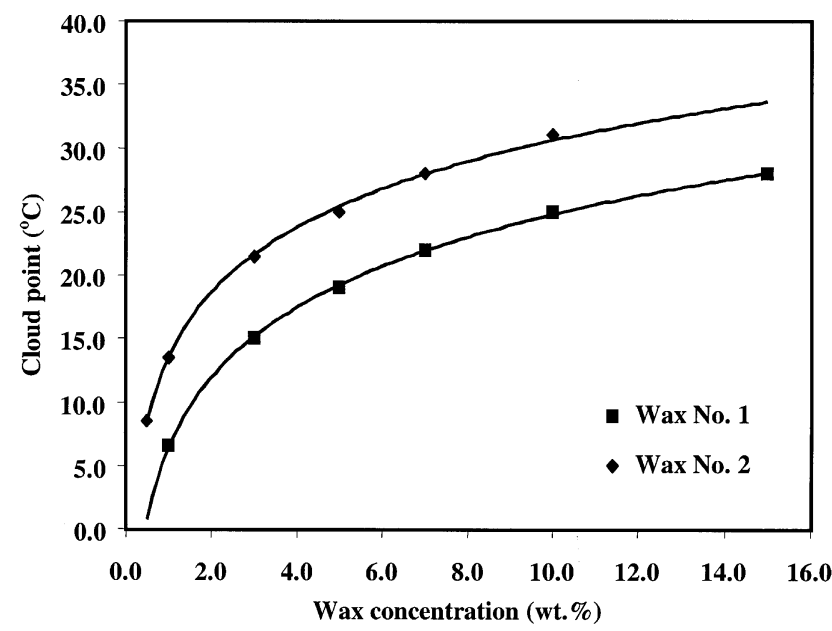

Figure 6. Cloud point temperatures of the two waxes in dodecane at various wax concentrations. 
the fact that the mean carbon number of the Wax No. 2 is 30 , whereas the mean carbon number of the Wax No. 1 is 26 .

Two model oils were prepared such that their cloud points are equal to $20^{\circ} \mathrm{C}$. Model Oil No. 1 was a mixture of $5.5 \mathrm{wt}$. $\%$ Wax No. 1 in dodecane. Model Oil No. 2 was a mixture of 2.4 wt. \% Wax No. 2 in dodecane. These model oils were used in the gel deposition experiments described in the following section.

\section{Gel Deposition Experiments Cold finger setup}

A laboratory cold finger setup simulates the cold wall of the pipeline in the presence of a warm wax-oil mixture. Figure 7 shows the cold finger apparatus, which was used to study the gel deposition on the cold surface. This apparatus consists of a temperature-controlled cold steel cylindrical finger submerged in a bath of warm wax-oil mixture. The surface area of the cold finger in contact with the warm oil is 30 $\mathrm{cm}^{2}$, and the volume of the reservoir is $3.5 \mathrm{dm}^{3}$.

\section{Flow loop setup}

The flow loop experiments simulate the gel deposition in the pipelines under cold environments (Singh et al., 2000). Figure 8 shows the laboratory flowloop, which was used in the wax deposition study. A sample of the wax-oil mixture was first heated to $30-35^{\circ} \mathrm{C}$ in a stirred vessel. During a typical run, the stirred vessel was maintained at a temperature above the cloud point. A specified wax-oil mixture was pumped from the stirred vessel through the test section that was cooled by a heat exchange jacket. The mixture returned to the stirred vessel through a reference section. Both the test section and the reference section had $5 / 8$ in. (16 mm)

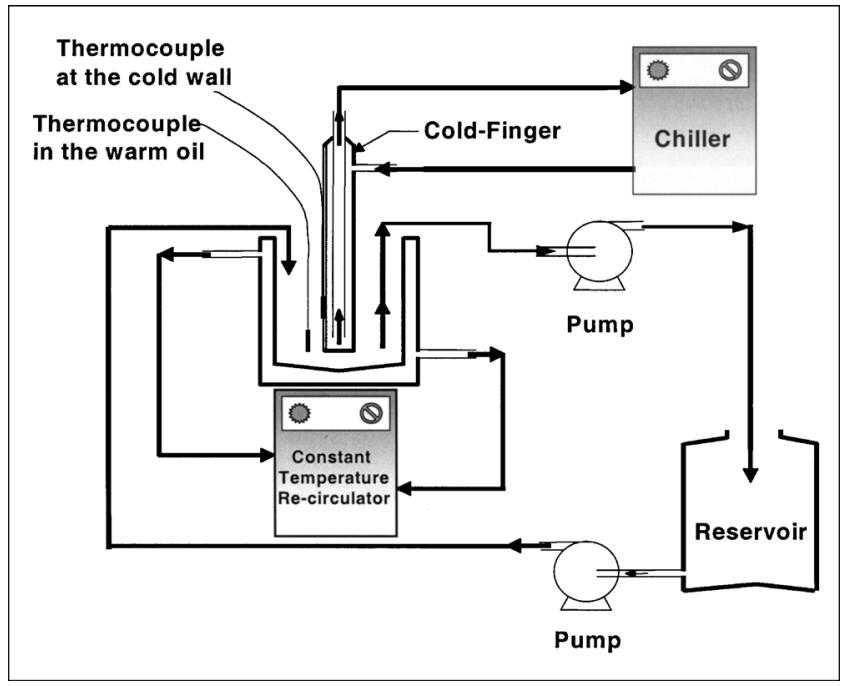

Figure 7. Cold finger apparatus.

OD steel tubing, each $8 \mathrm{ft}(2.4 \mathrm{~m})$ long. Both sections had pressure taps connected to differential pressure transducers at every two feet. The thickness of the gel deposit on the wall of the test section was determined from the increase in the differential pressure. A data acquisition system continuously recorded the wall temperature and inlet temperatures of the fluid along with differential pressure readings in the test and reference sections.

The test section of the flowloop also contains a spool piece, which is removed after each experiment and the gel deposit is collected from the spool piece. The molecular weight distributions of the gel deposits are analyzed using HTGC. The

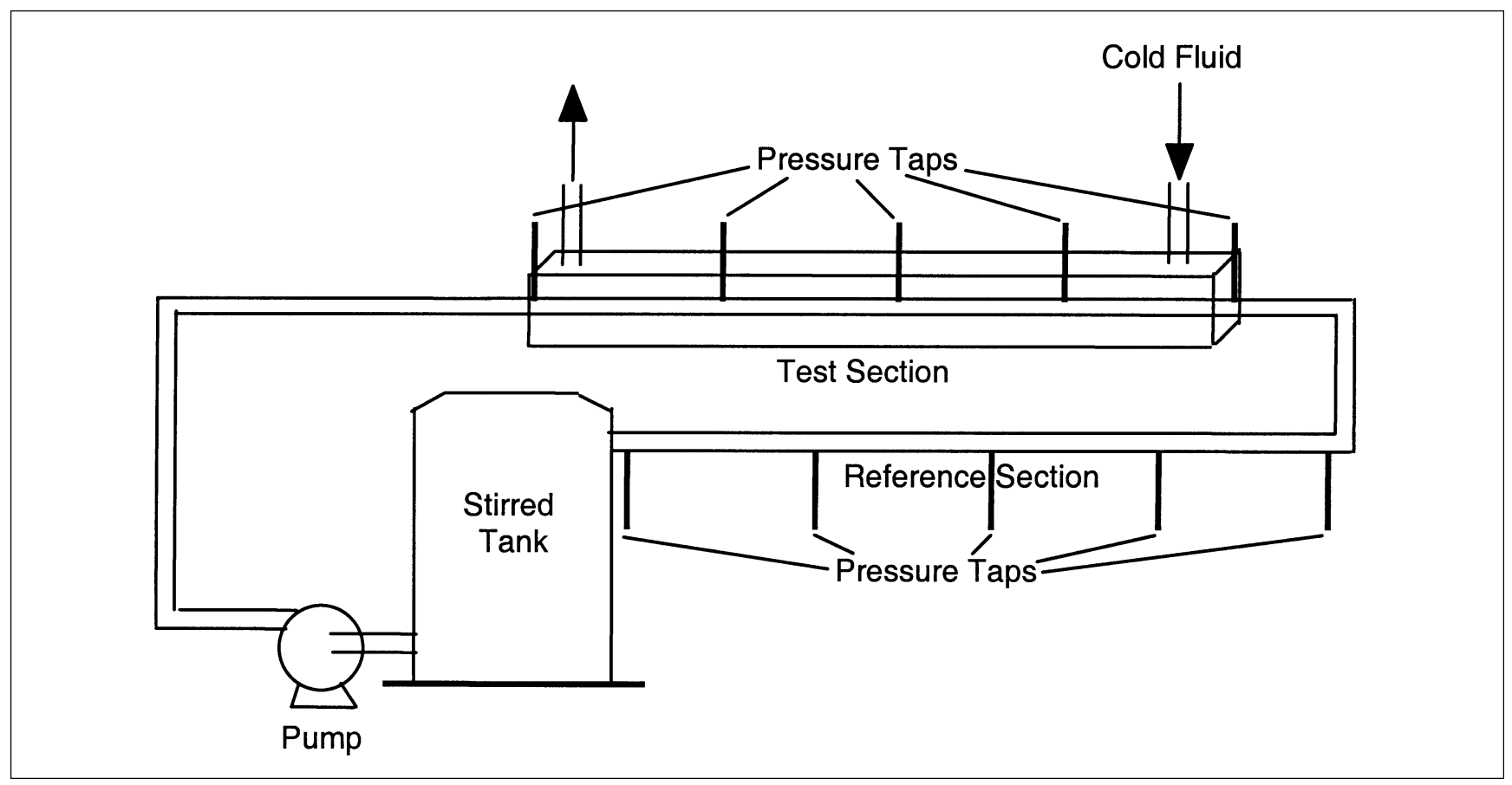

Figure 8. Laboratory flowloop setup. 
carbon-number distribution of various gel deposits collected at various time intervals reveal the critical carbon number as shown in Figure 3, which shows that the $\mathrm{CCN}$ of the system is 28.

\section{Experimental procedures}

The wax concentrations of both model oils were chosen such that the cloud points of both oils were $20^{\circ} \mathrm{C}$. Water was circulated through the outer jacket of the bath using a constant temperature recirculator to maintain the temperature of the wax-oil mixture at $25^{\circ} \mathrm{C}$, that is, $5^{\circ} \mathrm{C}$ above the cloud point. Chiller is used to maintain the temperature of the cold finger at $5^{\circ} \mathrm{C}, 10^{\circ} \mathrm{C}$, and $15^{\circ} \mathrm{C}$. A series of cold finger experiments were carried out using the two model oils. The mean film temperature of the thin gel deposits $\left(T_{\mathrm{gel}}\right)$ is defined as the average temperature between the cold finger temperature $\left(T_{\text {wall }}\right)$ and deposit-oil interfacial temperature $\left(T_{\text {int }}\right)$, which is the cloud point of the model oil. In order to keep the concentration of the wax in the warm wax-oil mixture constant throughout the experiment, a fresh wax-oil mixture was continuously circulated through the bath using two pumps (Milton Roy model CM4000).

Three different experiments were conducted with the model oil for $6 \mathrm{~h}, 12 \mathrm{~h}$, and $24 \mathrm{~h}$. The gel deposit was collected from the cold finger after each experiment. The gel deposits weighed $1.3 \pm 0.1$ grams, however, their compositions were different. Carbon number distributions of the gel deposits were analyzed by using high-temperature gas chromatography (HTGC). The solid fraction in the gel was analyzed using differential scanning calorimeter (DSC) and is found to be increasing with the deposition time (c.f. Figure 9) indicating that the gel deposition process is not a steady-state phenomenon.

The carbon number distributions of gel deposits collected from cold finger experiments on Model Oil No. 1 at the cold finger temperature of $15^{\circ} \mathrm{C}$ are shown in Figure 10 along with that of the oil sample. It can be seen that the weight fractions of all components do not increase with the deposition time. Actually, only the weight fractions of hydrocarbons having

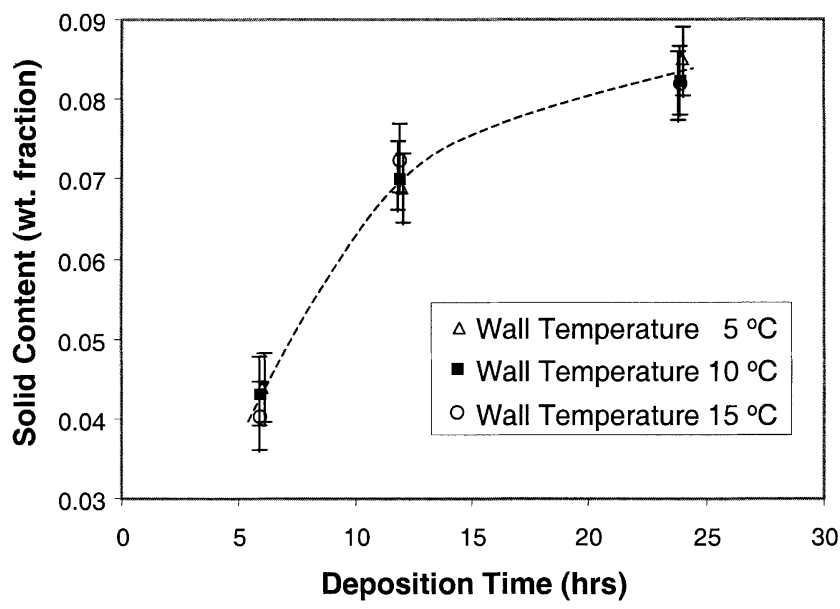

Figure 9. Weight fraction of the solid phase in the gel deposit as a function of the deposition time (Model Oil 2).

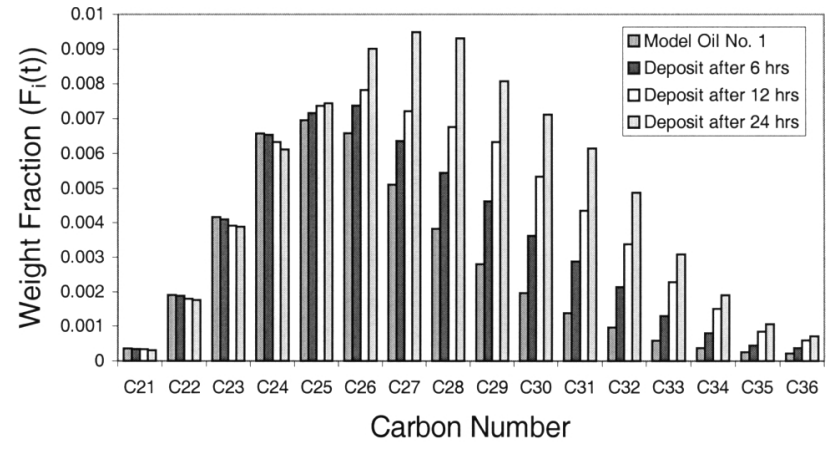

Figure 10. Carbon number distribution of gel deposits collected from cold finger experiments on Model Oil No. 1 at various deposition times.

Temperature of cold finger $=15^{\circ} \mathrm{C}$.

carbon number greater than a certain value, that is, the critical carbon number, increase with time, however, the weight fractions of the hydrocarbon having carbon numbers less than this critical value decrease with time (Singh et al., 2000).

In order to determine the critical carbon number of this system, the changes in the carbon number distributions of the gel deposits were observed. The carbon number distribution of the original Model Oil No. 1 was subtracted from those of the gel deposits, as shown in Figure 11. Figure 11 clearly shows that the weight fractions of hydrocarbons having carbon number greater than 24 increase with the deposition time, and weight fractions of those having carbon number less than 24 decrease with the time. The critical carbon number of this system is, therefore, 24 . This finding indicates that the hydrocarbons having carbon number greater than 24 diffuse into the gel deposit, and those having carbon number less than 24 diffuse out of the gel deposit. Hence, these results also indicate that the aging process of the gel deposit is a counterdiffusion phenomenon. Similar analysis for calculating the critical carbon number was also carried out for the Model Oil No. 2.

The gel deposit is composed of a liquid phase trapped in a solid phase. Hence, the composition of the gel can be easily

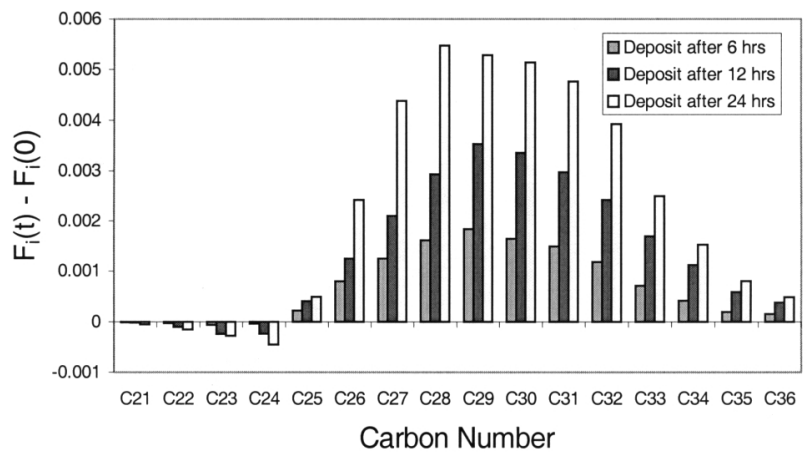

Figure 11. Changes in carbon number distribution of gel deposits collected from cold finger experiments on Model Oil No. 1 at various deposition times.

Temperature of cold finger $=15^{\circ} \mathrm{C}$. 
calculated if the compositions of the two phases and the weight fraction of the solid phase are known. The fraction of solid phase increases with time resulting in a change in the composition of the gel (c.f. Figure 9). The prediction of the composition of a gel having a certain solid content is achieved by predicting the compositions of the solid phase and the liquid phase, which constitute the gel. Hence, the prediction of the composition of the two phases is required to predict the composition of the gel and the critical carbon number of a wax-oil system. The following section describes the thermodynamic model developed for the predictions of the compositions of the two phases in a wax-oil system.

\section{Thermodynamic Modeling}

Coutinho (1999) applied excess Gibbs free energy models to describe the solid-liquid equilibria of paraffins. The energetic parameters used in these models were estimated by relating the interaction energies between pairs of molecules with their enthalpies of sublimation. The parameters were successfully used in the NRTL and UNIversal QUAsi-Chemical (UNIQUAC) models (Coutinho, 1999). Although it was reported (Coutinho, 1999) that the model provided a very good description of the composition of the liquid and solid phases in equilibrium, we will see that it fails in many situations. Therefore, the model is further modified for a better prediction of the wax precipitation. The following sections will describe the modeling equations of the UNIQUAC model developed by Coutinho (1999).

\section{Solid-Liquid Equilibrium}

The wax formation is treated as a solid-liquid equilibrium in a mixture of paraffins distributed between a liquid phase and an orthorhombic solid phase. This solid-liquid equilibrium can be described by the following equation (Coutinho et al., 1999) relating the composition of component $i$ in the solid and liquid phases with their nonideality and the pure component thermophysical properties presented in the literature

$$
\begin{array}{r}
\ln \frac{s_{i} \gamma_{i}^{s}}{x_{i} \gamma_{i}^{L}}=\frac{\Delta h_{m, i}}{R T_{m, i}}\left(\frac{T_{m, i}}{T}-1\right)+\frac{\Delta h_{t r, i}}{R T_{t r, i}}\left(\frac{T_{t r, i}}{T}-1\right) \\
-\frac{\Delta C p_{m, i}}{R}\left(\frac{T_{m, i}}{T}-\ln \frac{T_{m, i}}{T}-1\right) \\
y_{T i}=f_{s} s_{i}+\left(1-f_{s}\right) x_{i} \quad \text { and } \quad \sum_{i} y_{T i}=\sum_{i} s_{i}=\sum_{i} x_{i}=1
\end{array}
$$

where $y_{T i}, x_{i}$, and $s_{i}$ are the mol fractions of the $i$ th component in the oil feed, the liquid phase, and the solid phase, respectively, and $f_{s}$ is the fraction of the solid phase precipitated out. The correlations for the thermophysical properties of the pure components are given in the Appendix.

The amount and composition of the two phases can be calculated as a function of the temperature provided that the models for the nonideality of the solid and liquid phases are available.

\section{Liquid-Phase Nonideality}

The activity coefficient of an $i$ th component in the $n$-alkane liquid phase is expressed as the product of two contributions: a combinatorial part (entropic effects) accounting for the size difference, as well as free volume effects and residual part accounting for the energetic interactions among the components

$$
\gamma_{i}^{L}=\gamma_{i}^{\text {comb-fv }} \gamma_{i}^{\text {res }}
$$

Hydrocarbon mixtures are known to behave almost athermally, meaning that the activity coefficient is almost temperature-independent. In these cases, the residue contribution may be assumed to be small $\left(\gamma_{i}^{\text {res }} \approx 1\right)$ and the deviations from ideality in the liquid phase are considered to arise primarily from the shape and free-volume differences between the components.

In this work, the activity coefficient used for the liquid phase can be described by using Flory free-volume (Coutinho, 1999), which uses only a combinatorial-free-volume term without a residual contribution. The combinatorial term for Flory free-volume can be expressed in the following general form (Coutinho and Stenby, 1996)

$$
\ln \gamma_{i}^{\text {comb- } f v}=\ln \frac{\phi_{i}}{x_{i}}+1-\frac{\phi_{i}}{x_{i}}
$$

where $x_{i}$ is the mol fractions of the $i$ th component in the liquid phase and $\phi_{i}$ is the composition fraction of component $i$ in the liquid phase defined by

$$
\phi_{i}=\frac{x_{i}\left(V_{i}^{1 / 3}-V_{w i}^{1 / 3}\right)^{3.3}}{\sum_{j} x_{j}\left(V_{j}^{1 / 3}-V_{w j}^{1 / 3}\right)^{3.3}}
$$

where $V_{i}$ is the molar volume of an $i$ th component (Elbro et al., 1991) and $V_{w i}$ is the van der Waals volume of an $i$ th component (Bondi, 1968), as shown in the Appendix.

\section{Solid-Phase Nonideality}

In this study, the solid-phase nonideality was described by a well-known local composition model UNIQUAC which allows multisolid phases equilibrium calculation. The UNIQUAC equation used in this work can be written as (Coutinho, 1999; Abrams and Prausnitz, 1975)

$$
\begin{aligned}
\frac{g^{E}}{R T}=\sum_{i=1}^{n} s_{i} \ln \left(\frac{\Phi_{i}}{s_{i}}\right)+\frac{Z}{2} \sum_{i=1}^{n} q_{i} s_{i} \ln \frac{\theta_{i}}{\Phi_{i}} \\
-\sum_{i=1}^{n} s_{i} q_{i} \ln \left[\sum_{j=1}^{n} \theta_{j} \exp \left(-\frac{\lambda_{j i}-\lambda_{i i}}{q_{i} R T}\right)\right]
\end{aligned}
$$

with

$$
\begin{array}{r}
\lambda_{i i}=-\frac{2}{Z}\left(\Delta h_{s b l m_{i}}-R T\right), \quad \lambda_{j i}=\lambda_{j j}, \quad \Phi_{i}=\frac{s_{i} r_{i}}{\sum_{j=1}^{n} s_{j} r_{j}} \\
\text { and } \theta_{i}=\frac{s_{i} q_{i}}{\sum_{j=1}^{n} s_{j} q_{j}}
\end{array}
$$


where $Z$ is the coordination number and has a value of 6 for the $n$-alkane orthorhombic crystals, $\Delta h_{s b l m}$ is the enthalpy of sublimation of the pure $n$-alkane, and the structural parameters $r_{i}$ and $q_{i}$ are estimated to take into account the specificity of the interactions in the solid phase. Coutinho (1999) used a very simple and empirical approach by assuming that the representative interaction unit for $n$-alkanes in the solid phase is equivalent to an interaction unit of 10 "original" methylene units. Thus, the $r_{i}$ and $q_{i}$ values are obtained simply by dividing the original $r_{i \text { org }}$ and $q_{i \text { org }}$ values by the respective values for 10 methylene units

$$
\begin{aligned}
& r_{i}=\frac{r_{i \mathrm{org}}}{0.6744 \times n_{M U}}=0.1483 \times r_{i \mathrm{org}} \\
& q_{i}=\frac{q_{i \mathrm{org}}}{0.54 \times n_{M U}}=0.1852 \times q_{i \mathrm{org}}
\end{aligned}
$$

where $n_{M U}$ is the number of methylene units. The correlation for $r_{i \text { org }}$ and $q_{i \text { org }}$ are given in the Appendix. The activity coefficient of the $i$ th component in the solid phase was calculated using the following equation

$$
\begin{aligned}
\ln \gamma_{i}^{s}=\left[\frac{\partial\left(n g^{E} / R T\right)}{\partial n_{i}}\right]_{P, T, n_{j}}=1-\frac{\Phi_{i}}{s_{i}}+\ln \left(\frac{\Phi_{i}}{s_{i}}\right) \\
+\frac{Z}{2} q_{i}\left(1-\frac{\theta_{i}}{\Phi_{i}}+\ln \frac{\theta_{i}}{\Phi_{i}}\right)+q_{i}\left(1-\ln \frac{\theta_{i}}{s_{i}}\right) \\
\quad-q_{i} \sum_{j}\left(\frac{q_{j} s_{j} \tau_{i j}}{\sum_{m} s_{m} q_{m} \tau_{m j}}\right)+q_{i} \ln \left(\frac{q_{i}}{\sum_{j} s_{j} q_{j} \tau_{j i}}\right)
\end{aligned}
$$

where $n$ is the total number of mols in the oil feed, $n_{i}$ is the number of mols of the $i$ th component and $\tau_{j i}=\exp \left[-\left(\lambda_{j i}-\right.\right.$ $\left.\left.\lambda_{i i}\right) / q_{i} R T\right]$.

\section{Solution Procedure}

The objective is to calculate the compositions of the solid and liquid phases $\left(s_{i}\right.$ and $x_{i}$ ) of the wax-oil mixture for various temperatures. For the case of single solid phase, the compositions of the two phases $\left(s_{i}\right.$ and $\left.x_{i}\right)$ and the solid fraction $\left(f_{s}\right)$ can be calculated by solving the system of algebraic Eqs. 1 and 2 if the activity coefficients $\left(\gamma_{i}^{L}\right.$ and $\left.\gamma_{i}^{S}\right)$ are known. The activity coefficient in the liquid phase $\left(\gamma_{i}^{L}\right)$ and that in the solid phase $\left(\gamma_{i}^{S}\right)$ are also functions of the composition of the two phases $\left(s_{i}\right.$ and $x_{i}$ ) (Eqs. 3 and 10). Hence, the system of algebraic Eqs. 1 and 2 are numerically solved along with all other equations including Eq. 3 for $\gamma_{i}^{L}$ and Eq. 10 for $\gamma_{i}^{S}$ and the compositions of the solid and liquid phases $\left(s_{i}\right.$ and $x_{i}$ ) are calculated. For the case of multiphase equilibria, a multiphase flash algorithm is required. The algorithm of resolution of the Rachford-Rice equations is applied to multiphase systems as proposed by Leivobici and Neoschil (1995). Dauphin et al. (1999) published some experimental data for the composition of the solid phase $\left(s_{i}\right)$ and theoretical predictions will first be compared with their experimental results.

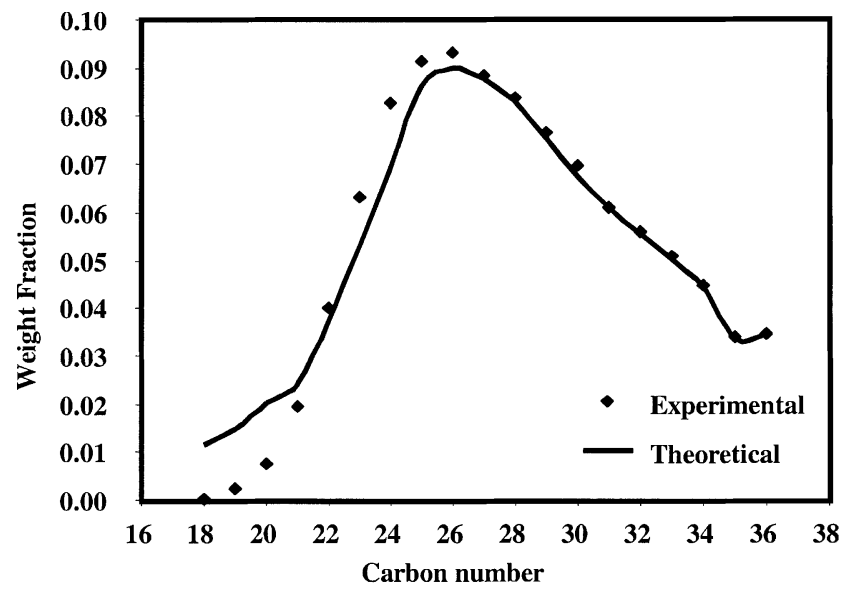

Figure 12. Comparison between experimental and Coutinho's theoretical solid-phase compositions at 283.25 K.

Experimental data from Dauphin et al. (1999).

This assumption of 10 methylene units, in a representative interaction unit for $n$-alkanes in the solid phase, was found to be invalid for many cases, because the representative interaction unit for $n$-alkanes in the solid phase depends on the chain lengths of the $n$-alkanes in the solid phase as shown below. Therefore, the number of methylene units in a representative interaction unit for $n$-alkanes in the solid phase is found to be a strong function of the mean chain length of the precipitated $n$-alkanes.

\section{Verification of the Thermodynamic Model}

The model developed in this work was first verified with the equilibrium data published in the literature. The literature data of solid-phase compositions at six different system temperatures taken from Dauphin et al. (1999) were used to verify the thermodynamic model developed in this study.

Figure 12 shows the relationship between weight fraction of solid phase and carbon number from experimental and theoretical data at $283.25 \mathrm{~K}$. The results showed that the experimental data matched very well with the theoretical data especially in the higher hydrocarbon range. However, as shown below in Figures 13 and 14, the existing model with the assumption of 10 methylene units fails to predict the experimental data at $303.15 \mathrm{~K}$ and $298.15 \mathrm{~K}$.

\section{Reason for the Discrepancy}

While estimating the structural parameters $r_{i}$ and $q_{i}$ in the UNIQUAC equation (Eq. 6), Coutinho (1999) used a very simple and empirical approach and assumed that the representative interaction unit for $n$-alkanes in the solid phase is equivalent to an interaction unit having 10 of the "original" methylene units. Thus, the $r_{i}$ and $q_{i}$ values are obtained simply by dividing the original $r_{i}$ and $q_{i}$ values by the respective values for 10 methylene units. This assumption of 10 methylene units was found to be invalid for many cases, because the representative interaction unit for $n$-alkanes in the solid phase depends on the chain lengths of the $n$-alkanes in the 


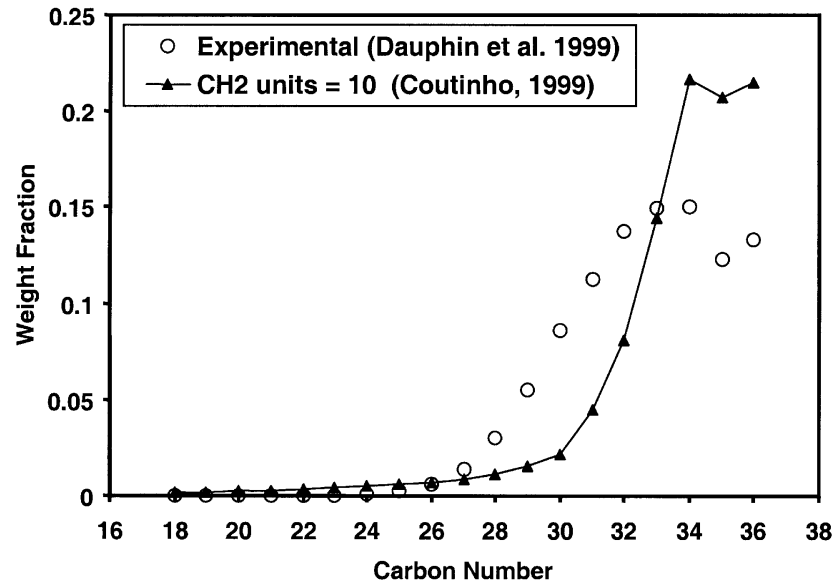

Figure 13. Comparison between experimental and Coutinho's theoretical solid-phase compositions at $303.15 \mathrm{~K}$.

Experimental data from Dauphin et al. (1999).

solid phase. Therefore, the number of methylene units in a representative interaction unit for $n$-alkanes in solid phase is found to be a strong function of the mean chain length of the precipitated $n$-alkanes. The optimum number of methylene units is obtained by minimizing the sum of the square of differences between experimental and theoretical results. Figure 15 shows that the optimum number of methylene units is a strong function of the mean carbon number in the deposit.

Figures 16 and 17 show an improvement in the prediction of the solid-phase composition by using the optimum number of methylene units at $303.15 \mathrm{~K}$ and $298.15 \mathrm{~K}$, respectively.

The theoretical model (flash calculations) is able to successfully predict the composition of the solid phase. That is, we give the oil feed composition $y_{T i}$, and we can calculate the composition of the liquid phase $\left(x_{i}\right)$ and the solid phase $\left(s_{i}\right)$. Figure 18 shows how the compositions of the gel deposit are calculated starting from a given composition of the oil

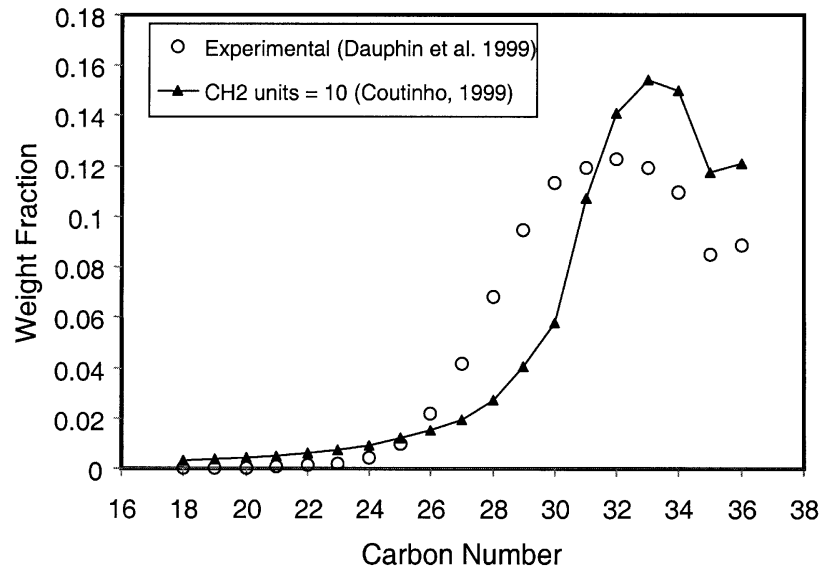

Figure 14. Comparison between experimental and Coutinho's theoretical solid-phase compositions at $298.15 \mathrm{~K}$.

Experimental data from Dauphin et al. (1999).

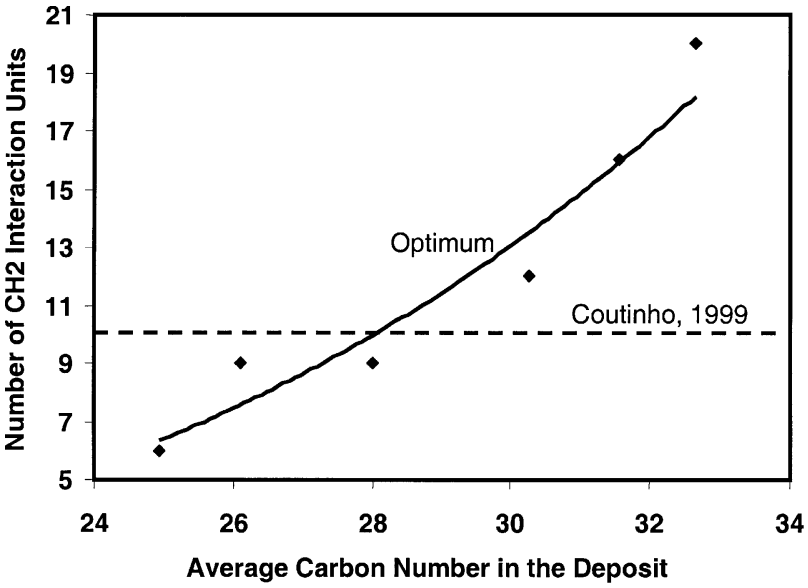

Figure 15. Optimum number of methylene units as a function of the mean carbon number of the deposit.

feed. The first step is to calculate the compositions of the solid and the liquid phase resulting from the phase separation of the oil feed at a lower temperature. Hence, the left half of the Figure 18 [calculation of the compositions of the two phases $\left(x_{i}\right.$ and $\left.\left.s_{i}\right)\right]$ has been successfully achieved as explained in the previous section. Calculation of the composition of the gel deposit $\left(d_{i}\right)$ is the next step.

The composition of the $i$ th species $\left(d_{i}\right)$ in the gel deposit, having a certain solid fraction (say $w$ ), is calculated from the predicted composition of the solid phase $\left(s_{i}\right)$ and the liquid phase $\left(x_{i}\right)$ as follows

$$
d_{i}=w \times s_{i}+(1-w) \times x_{i}
$$

The carbon number distributions of gel deposits, constructed using the theoretical data $s_{i}$ and $x_{i}$, were obtained for three different deposition times as shown in Table 2. The

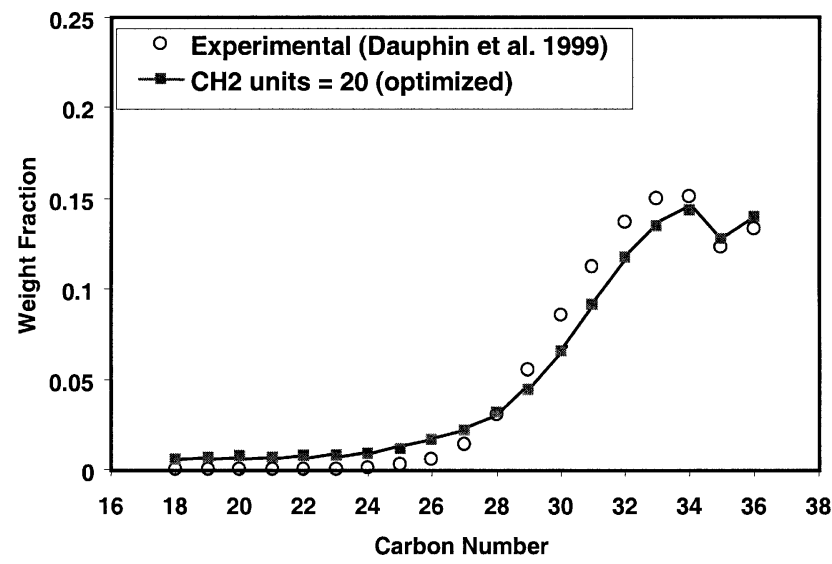

Figure 16. Comparison between experimental and current theoretical solid-phase compositions at 303.15 K using optimized number of $\mathrm{CH}_{2}$ units.

Experimental data from Dauphin et al. (1999). 


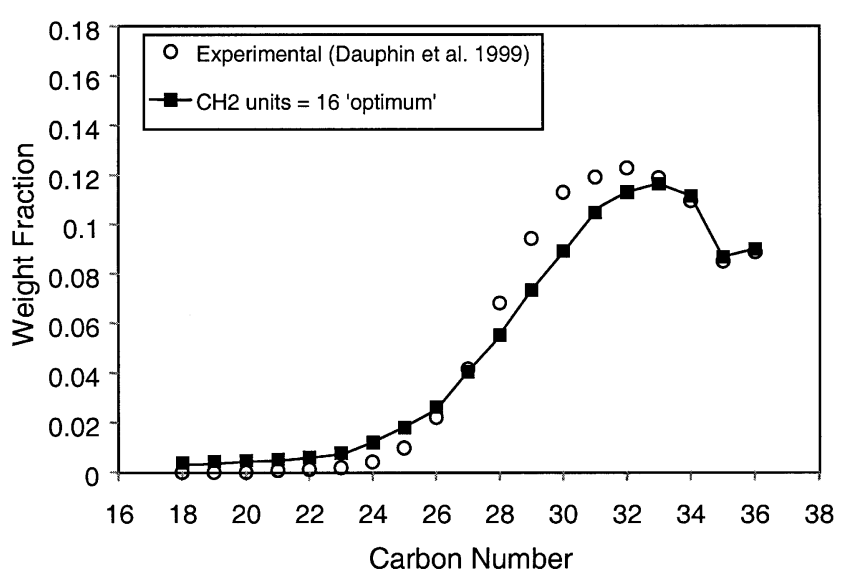

Figure 17. Experimental vs. current theoretical solidphase compositions at $298.15 \mathrm{~K}$ using optimized number of $\mathrm{CH}_{2}$ units.

Experimental data from Dauphin et al. (1999).

solid fraction $(w)$ for the three different deposition times are experimentally determined (c.f. Figure 9). The carbon number distribution of the original model oil was subtracted with those of gel deposits, as shown in Figure 11. The changes in carbon number distributions were observed and the critical carbon number was determined.

The analysis of the theoretically calculated compositions of the gels $\left(d_{i}\right)$ corresponding to various deposition times was similar to the analysis of the experimentally determined gel compositions (c.f. Figures 10 and 11). From the analysis, the theoretical value of the critical carbon number is evaluated for the system published by Dauphin et al. (1999). The experimental value of the critical carbon number is calculated from the equilibrium data published by Dauphin et al. (1999). Figure 19 shows the relationship between the critical carbon number and the system temperature. The results show that there is an excellent agreement between the experimental and theoretical data. The $\mathrm{CCN}$ is very sensitive to the wall temperature, and it increases from 18 to 28 over the range of 35 $\mathrm{K}$.

The above results confirm that the developed model in this study is successfully able to predict the composition of the solid phase obtained after cooling down a model oils, as well as the critical carbon number of the oil system.

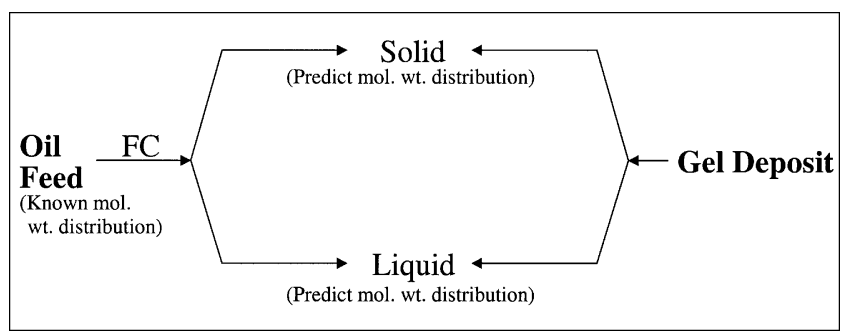

Figure 18. Calculation of the composition of the gel deposit from the composition of the oil feed.
Table 2. Contribution of Gel Deposits Using Theoretical Data

\begin{tabular}{ccc}
\hline $\begin{array}{c}\text { Deposition } \\
\text { Time }\end{array}$ & $\begin{array}{c}\text { Solid Wax } \\
\text { Content of }\end{array}$ & $\begin{array}{c}\text { Gel Deposit } \\
\text { Composition }\end{array}$ \\
\hline$t_{1}$ & $w_{1}$ & $w_{1} s+\left(1-w_{1}\right) x$ \\
$t_{2}$ & $w_{2}$ & $w_{2} s+\left(1-w_{2}\right) x$ \\
$t_{3}$ & $w_{3}$ & $w_{3} s+\left(1-w_{3}\right) x$ \\
\hline
\end{tabular}

$s$ and $x$ are fractions of solid phase and liquid phase, respectively.

\section{Results and Discussions Cloud point temperatures}

The cloud point temperature of a wax-oil mixture is predicted by calculating the fraction of the solid phase $f_{s}$ by solving Eqs. 1 and 2 for various temperatures. The solubility of the wax in the oil increases as the temperature increases, therefore, the fraction of the solid phase $f_{s}$ decreases as temperature increases and the temperature at which $f_{s}=0$ is defined as the cloud point temperature of the wax-oil mixture. This temperature can easily be determined theoretically by plotting the fraction of the solid phase $f_{s}$ as a function of the temperature and extrapolate to $f_{s}=0$. Figure 20 shows the comparison between the experimental and the theoretical cloud point temperatures of the mixtures of Wax No. 1 in dodecane. There is an excellent agreement between the experimental data and the theoretical prediction. However, a small deviation from experimental values is observed at higher wax concentrations.

Figure 21 shows the comparison between the experimental and the theoretical cloud point temperatures of the mixture of Wax No. 2 in dodecane. It can be seen that the experimental data are in the excellent agreement with the theoretical predictions.

\section{Critical Carbon Number}

Table 3 shows the comparison of experimental and theoretical values of the critical carbon number of the Model Oil

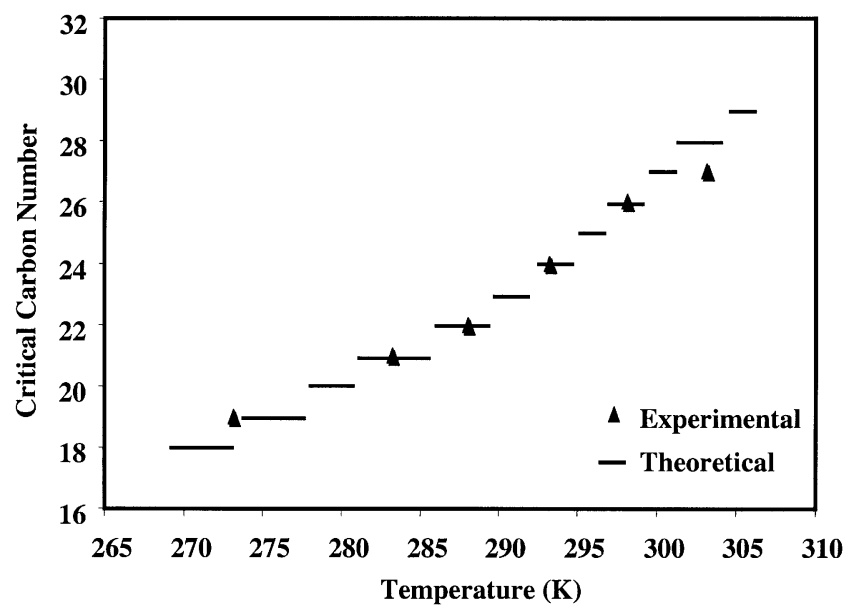

Figure 19. Experimental vs. predicted critical carbon numbers as a function of temperature for the wax-oil system analyzed by Dauphin et al. (1999). 


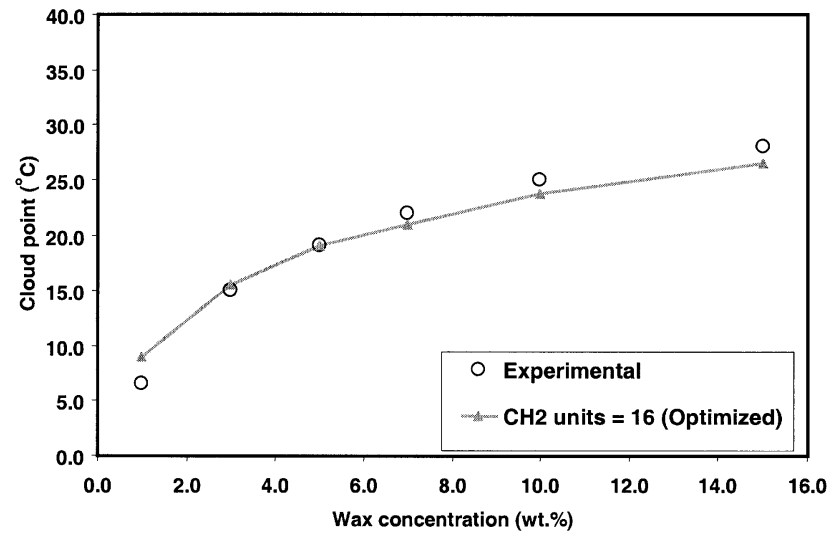

Figure 20. Experimental vs. theoretical cloud point temperatures of the mixtures of Wax No. 1 in dodecane.

No. 1, No. 2 and the flowloop oil system. It can be seen that the experimental data are in an excellent agreement with the theoretical data for both model oils, as well as the flowloop oil system.

The model oil system used for the flowloop experiment is a 3:1 mixture of mineral oil and kerosene. The Model Wax No. 2 was added to the model oil to prepare the model wax-oil system. The molecular weight distribution of the model system used in the flowloop is published earlier (Singh et al., 2000). The theoretical model assumes the solvent (3:1 mineral oil and kerosene) as a multicomponent paraffin mixture. The theoretical model also successfully predicts the critical carbon number of the model oil used in the flowloop experiment (c.f. Figure 3) to be equal to 28 (as shown in Table 3).

The critical carbon number of a real crude oil can be experimentally determined by the HTGC analyses of the gel deposits collected from the cold finger apparatus. The experimental procedure for the real crude will be identical to the one described in the experimental section. The real crude oil is a complex mixture of numerous hydrocarbons such as

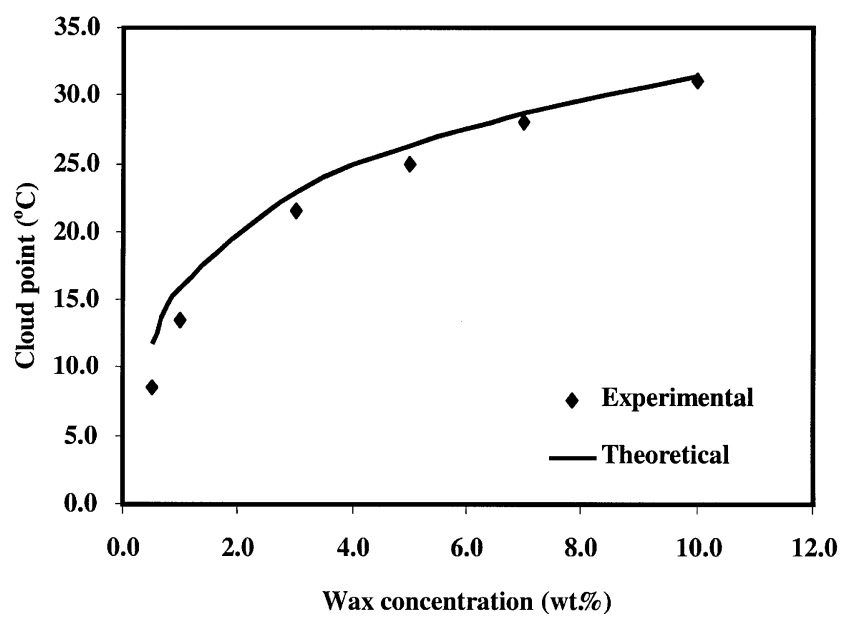

Figure 21. Experimental vs. theoretical cloud point values of mixtures of Wax No. 2 in dodecane.
Table 3. Experimental vs. Predicted Critical Carbon Numbers of Various Model Systems at Different Temperatures

\begin{tabular}{cccc}
\hline & & \multicolumn{2}{c}{ Critical Carbon Number } \\
\cline { 3 - 4 } Model Oil System & Temp. $\left({ }^{\circ} \mathrm{C}\right)$ & Exp. & Pred. \\
\hline Model oil No. 1 & 15 & 24 & 24 \\
& 10 & 23 & 23 \\
& 5 & 23 & 22 \\
\hline Model oil No. 2 & 15 & 25 & 25 \\
& 10 & 24 & 24 \\
& 5 & 24 & 23 \\
\hline Flowloop system & 11.3 & 28 & 28 \\
\hline
\end{tabular}

paraffins, aromatics, naphthenes, resins, and asphaltenes. The mathematical model developed for the paraffin mixtures has been shown quite successful in predicting the critical carbon numbers of the paraffin mixtures. There is still a need to understand how the presence of other hydrocarbons (such as naphthenes, aromatics, and so on) influence the solid-liquid equilibrium of hydrocarbons distributed in a liquid and solid phase. The interactions among cyclic groups, aromatic rings, and linear paraffinic groups present in various hydrocarbons would play an important role in the calculation of the activity coefficients of various components in the crude oil. The group contributions of these interactions may be estimated using the UNIQUAC model, similar to the estimation of the interaction between $\mathrm{CH}_{2}$ and $\mathrm{CH}_{3}$ groups in the paraffin molecules. Once the activity coefficients of various components in the liquid phase and the solid phase are accurately estimated, Eqs. 1 and 2 may be used to calculate the composition of the solid phase and the liquid phase. As a first approximation, one might neglect the aromatic interaction.

\section{Conclusions}

High molecular weight paraffins from stable crystals at low temperatures that leads to the formation of gels with a complex morphology. The model systems of wax and oil were used to understand the gelation process of these mixtures. A cross-polarized light microscope coupled with a temperature-control stage was used to determine the cloud point temperature of various wax-oil mixtures. A series of laboratory cold finger experiments were carried out for various deposition times to study the physics of the aging process of the gel deposits that leads to an increase in the wax content of the deposited gel with time. It was observed that there is a critical carbon number $(\mathrm{CCN})$, where the wax molecules having carbon number above $\mathrm{CCN}$ diffuse into the gel deposit, while molecules having carbon number below $\mathrm{CCN}$ diffuse out of the gel deposit. A thermodynamic model was developed to predict the cloud point temperatures, as well as the critical carbon numbers of the wax-oil mixtures. The liquid phase nonideality was described by Flory free-volume equation accounting for the differences in size and free volume of molecules in paraffinic mixtures. The critical carbon number not only depends on the composition of the wax-oil mixture, but also on the wall temperature. The critical carbon number increases with increasing wall temperature. The UNIQUAC equation was applied to describe the solid phase nonideality. 
The values predicted for both the cloud point temperatures and the critical carbon numbers of the model oils, using the thermodynamic model developed in this study, showed a good agreement with the experimental data.

\section{Notation}

$$
\begin{aligned}
& f=\text { fugacity } \\
& g=\text { Gibbs free energy, } \mathrm{kJ} / \mathrm{mol} \\
& h=\text { enthalpy, } \mathrm{kJ} / \mathrm{mol} \\
& R=\text { ideal gas constant } \\
& T=\text { temperature, } \mathrm{K} \\
& V=\text { molar volume }, \mathrm{cm}^{3} / \mathrm{mol} \\
& q=\text { surface area parameter, UNIQUAC } \\
& r=\text { volume parameter, UNIQUAC } \\
& s=\text { solid-phase molar fraction } \\
& x=\text { liquid-phase molar fraction } \\
& Z=\text { coordination number } \\
& \gamma=\text { activity coefficient } \\
& \phi=\text { volume fraction } \\
& \lambda=\text { interaction parameter } \\
& \theta=\text { area fraction }
\end{aligned}
$$

\section{Superscripts}

$$
\begin{aligned}
\text { comb } & =\text { combinatorial } \\
\text { res } & =\text { residual } \\
f v & =\text { free volume } \\
E & =\text { excess } \\
L & =\text { liquid } \\
S & =\text { solid }
\end{aligned}
$$

\section{Subscripts}

$$
\begin{aligned}
i & =\text { component } \\
m & =\text { melting } \\
n & =\text { carbon number } \\
\operatorname{tr} & =\text { solid-solid transition } \\
\text { sblm } & =\text { vaporization } \\
\operatorname{vap} & =\text { vaporization } \\
w & =\text { van der Waals }
\end{aligned}
$$

\section{Literature Cited}

Abdallah, D. J., S. A. Sirchio, and R. G. Weiss, "Hexatriacontane Organogels. The First Determination of the Conformation and Molecular Packing of a Low-Molecular-Mass Organogelator in Its Gelled State," Langmuir, 16, 7558 (2000).

Abrams, D. S., and J. M. Prausnitz, "Statistical Thermodynamics of Liquid Mixtures: A New Expression for the Excess Gibb's Free Energy of Partly or Completely Miscible Systems," AIChE J., 21, 116 (1975).

Bondi, A., Physical Properties of Molecular Crystals, Liquids, and Glasses, Wiley, New York (1968).

Chang, C., D. V. Boger, and Q. D. Nguyen, "Influence of Thermal History on the Waxy Structure of Statically Cooled Waxy Crude Oil," SPE J., 5, 148 (2000).

Coutinho, J., S. I. Andersen, and E. H. Stenby, "Evaluation of Activity Coefficient Models in Prediction of Alkane Solid-Liquid Equilibrium," Fluid Phase Equil., 103, 23 (1995).

Coutinho, J. A. P., and E. H. Stenby, "Predictive Local Composition Models for Solid/Liquid Equilibrium in $n$-Alkane Systems: Wilson Equation for Multicomponent Systems," Ind. Eng. Chem. Res., 35, 918 (1996).

Coutinho, J. A. P., "Predictive Local Composition Models: NTRL and UNIQUAC and their Application to Model Solid-Liquid Equilibrium of $n$-Alkanes," Fluid Phase Equilibria, 159, 447 (1999).

Dauphin, C., J. L. Daridon, J. A. P. Coutinho, P. Baylere, and M. Potin-Gautier, "Wax Content Measurements in Partially Frozen Paraffinic Systems," Fluid Phase Equil., 161, 135 (1999).

Dirand, M., V. Chevallier, E. Provost, M. Bouroukba, and D. Petitjean, "Multicomponent Paraffin Waxes and Petroleum Solid Deposits: Structural and Thermodynamic State," Fuel, 77, 1253 (1998).
Dorset, D. L., "Chain Length and the Consolubility of $n$-Paraffins in the Solid State," Macromolecules, 23, 623 (1990).

Elbro, H. S., A. Fredenslund, and P. Rasmussen, "Group Contribution Method for the Prediction of Liquid Densities as a Function of Temperature for Solvents, Oligomers, and Polymers," Ind. Eng. \& Chemistry Res., 30, 2576 (1991).

Hansen, A. B., E. Larsen, W. B. Pederson, A. B. Nielsen, and H. P. Ronningsen, "Wax Precipitation from North Sea Crude Oils. 3. Precipitation and Dissolution of Wax Studied by Differential Scanning Calorimetry," Energy \& Fuels, 5, 914 (1991).

Hansen, J. H., "A Thermodynamic Model for Predicting Wax Formation in Crude Oils," AIChE J., 38, 1937 (1988).

Holder, G. A., and J. Winkler, "Wax Crystallization from Distillate Fuels: I. Cloud and Pour Phenomena Exhibited by Solutions of Binary $n$-Paraffin Mixtures," J. Inst. Petrol., 51, 228 (1965).

Lira-Galeana, C., A. Firoozabadi, and J. M. Prausnitz, "Thermodynamics of Wax Precipitation in Petroleum Mixture," AIChE J., 42, 239 (1996).

Leibovici, C. F., and J. Neoschil, "Solution of Rachford-Rice Equations for Multiphase Systems," Fluid Phase Equil., 112, 217 (1995).

Morgan, D. L., and R. Kobayashi, "Extension of Pitzer CSP Models for Vaporization to Long-Chain Hydrocarbons," Fluid Phase Equil., 94, 51 (1994).

Neto, F. R. A., J. N. Cardoso, and S. A. Pereira, "Application of High Temperature High Resolution Gas Chromatography to Paraffinic Deposits in Petroleum Production Pipelines," J. High Res. Chrom., 17, 259 (1994).

Pauly, J., C. Dauphin, and J. L. Daridon, "Liquid-Solid Equilibria in a Decane Plus Multi-Paraffins System," Fluid Phase Equil., 149, 191 (1998).

Singh, P., and H. S. Fogler, "Fused Chemical Reactions: The Use of Dispersion to Delay Reaction Time in Tubular Reactors," Ind. Eng. Chem. Res., 37, 2203 (1998).

Singh, P., H. S. Fogler, and N. Nagarajan, "Prediction of the Wax Content of the Incipient Wax-Oil Gel in a Flow Loop: An Application of the Controlled-Stress Rheometer," J. Rheol., 46, 1437 (1999).

Singh, P., R. Venkatesan, H. S. Fogler, and N. Nagarajan, "Formation and Aging of Incipient Thin Film Wax-Oil Gels," AIChE J., 46, 1059 (2000).

Snyder, R. G., M. C. Goh, V. J. P. Srivatsavoy, H. L. Strauss, and D. L. Dorset, "Measurement of the Growth Kinetics of Microdomains Binary $n$-Alkane Solid Solutions by Infrared Spectroscopy," J. of Phys. Chemistry, 96, 10008 (1992).

Soave, G., "Equilibrium Constants from a Modified Redlich-Kwong Equation of State," Chem. Eng. Sci., 27, 1197 (1972).

Tao, Y. X., R. W. Besant, and K. S. Rezkallah, "A Mathematical Model for Predicting the Densification and Growth of Frost on a Flat Plate," Int. J. Heat Mass Transfer, 36, 353 (1993).

Wardhaugh, L. T., and D. V. Boger, "The Measurement and Description of the Yielding Behavior of Waxy Crude Oil," J. Rheol., 35, 1121 (1991).

Won, K. W., "Continuous Thermodynamics for Solid-Liquid Equilibria: Wax Formation from Heavy Hydrocarbon Mixtures," paper 27A, AIChE Meeting, Houston, TX (1985).

Won, K. W., "Thermodynamics for Solid-Liquid Equilibria: Wax Phase Formation from Heavy Hydrocarbon Mixtures," Fluid Phase Equil., 30, 265 (1986).

\section{Appendix}

\section{Thermophysical properties}

$$
\begin{array}{r}
T_{m}[\mathrm{~K}]=0.040 C_{n}^{3}-2.2133 C_{n}^{2}+46.197 C_{n}-45.777 \\
\text { for } C_{n}<C_{16} \\
T_{m}[\mathrm{~K}]=0.0028 C_{n}^{3}-0.3185 C_{n}^{2}+13.559 C_{n}+143.15 \\
\text { for } C_{n} \geq C_{16} \\
T_{t r}[\mathrm{~K}]=-0.0038 C_{n}^{3}-0.1159 C_{n}^{2}+13.386 C_{n}+108.79 \\
\text { for } C_{n}<C_{16}
\end{array}
$$




$$
\begin{array}{r}
T_{t r}[\mathrm{~K}]=0.0038 C_{n}^{3}-0.4126 C_{n}^{2}+16.741 C_{n}+99.885 \\
\text { for } C_{n} \geq C_{n 16} \quad \text { (A4) } \\
\Delta h_{m}[\mathrm{~kJ} / \mathrm{mol}]=-0.0009 C_{n}^{3}-0.0011 C_{n}^{2}+3.6119 C_{n}-16.282 \\
\text { for } C_{n} \leq C_{19} \quad \text { (A5) } \\
\Delta h_{m}[\mathrm{~kJ} / \mathrm{mol}]=0.0036 C_{n}^{3}-0.2376 C_{n}^{2}+7.400 C_{n}-34.814 \\
\text { for } C_{n} \geq C_{19} \quad \text { (A6) } \\
\Delta h_{t r}[\mathrm{~kJ} / \mathrm{mol}]=0.0009 C_{n}^{3}+0.0011 C_{n}^{2}+0.1668 C_{n}+3.693 \\
\text { for } C_{n}<C_{19} \quad \text { (A7) } \\
\Delta h_{t r}[\mathrm{~kJ} / \mathrm{mol}]=-0.0032 C_{n}^{3}+0.2353 C_{n}^{2}-3.912 C_{n}+25.261 \\
\Delta h_{s b l m}=\Delta h_{\text {vap }}+\Delta h_{m}+\Delta h_{t r}
\end{array}
$$

\section{Molar volume of component $i$}

Molar volume of $n$-alkane can be calculated using Group Contribution Method given by Elbro et al. (1991)

$$
V=\sum n_{i} \Delta v_{i}
$$

$\Delta v_{i}$ is given by the following simple polynomial function

$$
v_{i}=A_{i}+B_{i} T+C_{i} T^{2}
$$

Table A1 shows group contributions for the saturated molar volume. Van der Waals volume of normal alkane is given by Bondi (1968)

$$
V_{w i}=10.23 \cdot i
$$

where $i$ is number of methylene groups in the chain of $n$-alkane.

$r_{i}$ and $q_{i}$ values

$$
\begin{gathered}
r_{i \mathrm{org}}=(i+0.0672) \times 0.6744 \\
q_{\text {iorg }}=(i+0.1141) \times 0.54
\end{gathered}
$$

\section{Mathematical Analysis of $\mathrm{CCN}$}

Crude oil is a mixture of hydrocarbons with a broad range of molecular weight distribution. Changes in the physical

Table A1. Group Contributions for Saturated Molar Volume

\begin{tabular}{cccc}
\hline & \multicolumn{3}{c}{ Group Vol. Temp. Constant } \\
\cline { 2 - 4 } Group & $A, \mathrm{~cm}^{3} / \mathrm{mol}$ & $\times 10^{3} B, \mathrm{~cm}^{3} / \mathrm{mol}$ & $\times 10^{5}$ \\
\hline $\mathrm{CH}_{3}$ & 18.960 & 45.58 & 0 \\
$\mathrm{CH}_{2}$ & 12.520 & 12.94 & 0 \\
\hline
\end{tabular}

conditions (temperature and pressure) can cause a separation of this mixture into two or more phases. If the temperature of a warm waxy crude oil (a single liquid phase) is decreased, it separates into two (liquid and solid) phases.

Let $y_{T i}$ be the mole fraction of the $i$ th component (hydrocarbon with $i$ carbon atoms) in the bulk crude oil. The bulk crude oil temperature is assumed to be higher than the cloud point and hence it is a single-phase mixture (liquid phase)

$$
\Rightarrow \sum_{i=1}^{N} y_{T i}=1
$$

The temperature at the wall is below the cloud point and the gel deposit is a two-phase mixture (solid and liquid phase). Let $x_{i}$ and $s_{i}$ be the mole fractions of the $i$ th component (hydrocarbon with $i$ carbon atoms) in the liquid and solid phases of the gel, respectively

$$
\begin{gathered}
\Rightarrow \sum_{i=1}^{N} x_{i}=1 \\
\Rightarrow \sum_{i=n}^{N} s_{j}=1 \quad \text { and } \quad s_{i}=0 \quad \text { for } \quad 1<i<n-1
\end{gathered}
$$

where hydrocarbons having at least $n$ carbon atoms are contributing to the solid phase.

\section{Relationship between $y_{T i}$ and $x_{i}$}

Let $f_{s i}$ be the fraction of $i$ th component precipitating out as a solid phase in the gel. The mole fractions $s_{i}$ in the solid phase can be expressed as

$s_{i}=\frac{f_{s i}}{f_{x}} y_{T i}$ where $f_{s}=\sum_{i=n}^{N} f_{s i} y_{T i} \quad$ and $\quad f_{s i}=0$

$$
\text { for } 1<i<n-1
$$

The liquid phase mole fractions $y_{T i}$ in the gel phase can be expressed as

$$
x_{i}=\frac{1-f_{s i}}{1-f_{s}} y_{T i}
$$

The radial molar flux of $i$ th component is given by

$$
J_{i}^{R}=k_{i}\left(y_{T i}-x_{i}\right)=k_{l} y_{T i}\left(\frac{f_{s i}-f_{s}}{1-f_{s}}\right)
$$

From the above expression, the radial flux is positive (from bulk to the wall) only for the components having $f_{s i}>f_{s}$. For 
$l<i<n-1, f_{s i}=0$ and hence

$$
J_{i}^{R}=k_{l} y_{T i}\left(\frac{-f_{s}}{1-f_{s}}\right)<0
$$

This implies that the hydrocarbons with carbon atoms less than $n$ will diffuse from the wall to the bulk.

\section{Definition of the CCN}

The $\mathrm{CCN}$ is defined as the minimum number of carbon atoms in a hydrocarbon ( $n$-alkane) molecule above which

$$
\begin{gathered}
J_{i}^{R}>0 \text { for } \quad i>C C N \\
\Rightarrow f_{s i}>f_{s} \text { for } i>C C N
\end{gathered}
$$

and these molecules diffuse from the bulk to the wall and deposit in the gel phase. Also,

$$
\begin{aligned}
& f_{s i}=0<f_{s} \text { for } 1<i<n-1 \\
& \Rightarrow C C N \geq n
\end{aligned}
$$

\section{Effect of Temperature on CCN}

The solubility of $n$-alkanes increases with increase in temperature. Therefore, $n$ increases as the wall temperature is increased. Because $C C N \geq n$, the $\mathrm{CCN}$ also increases with increase in temperature.

Manuscript received Aug. 18, 2000, and revision received Apr. 16, 2001. 